\title{
A pilot study investigating research design feasibility using pre-post measures to test the effect of music therapy in psychiatry with people diagnosed with personality disorders
}

\author{
Niels Hannibal ${ }^{12}$ * , Inge Nygaard Pedersen ${ }^{12}$, Lars Ole Bonde ${ }^{12}$, Lars Rye Bertelsen ${ }^{12}$ \\ 1 Department of Communication and Psychology, the Music Therapy Education, Aalborg University, \\ Aalborg, Denmark \\ 2 Music Therapy Clinic, Aalborg University Hospital, Psychiatry. Aalborg, Denmark \\ *hannibal@hum.aau.dk
}

Received: 5 January 2018 Accepted: 28 January 2019 Published: 1 March 2019

Editor: Alexander Crooke Reviewers: Jason Kenner, Cherry Hense

\begin{abstract}
Introduction: The objectives of the pilot study were (a) to investigate the feasibility of the research design (referral procedure, data collection procedure, measurement tools, and treatment doses/frequency); (b) to develop and evaluate the PROMT treatment manual; and (c) to test the use of flexible and or multiple interventions as part of the treatment options. Findings from this investigation aim to prepare for a future outcome study of music therapy treatments for patients with personality disorders, that are inspired by analytically oriented music psychotherapy and mentalizationbased treatment.

Methods: Four participants assessed and diagnosed with personality disorder received 40 sessions of individual music therapy. Pre and post measures of outcome variables looking at attachment style, helping alliance, symptom severity, interpersonal problems, and quality of life were evaluated for inclusion in the design. Interviews with clinicians were used to further evaluate the manual.

Results: All participants completed treatment. Outcome measurement provided usable information and also showed some positive changes in the four cases. The research design was found to be usable for a larger study. The treatment manual was evaluated as usable, but specification on how to use mentalization-based treatment in music-based interventions is required in a future manual.

Discussion: In light of the current findings, we discuss several factors relevant to a possible future outcome study, including the research design, theoretical model, and specific elements of the treatment manual. We also discuss the potential of using flexible and/or multiple interventions as part of the treatment options. We conclude that integration of mentalization-based treatment into music therapy seems promising, but further development of the treatment manual is needed.
\end{abstract}


Keywords: pilot study, personality disorder, process oriented music therapy, mentalization-based treatment

\section{Introduction}

The Music Therapy Clinic at the Psychiatry Department of Aalborg University Hospital in Denmark has provided music therapy services since 1994. This clinic is an integrated unit and a product of collaboration between Aalborg University and Aalborg University Hospital. More than 300 patients with personality disorders have received individual or group music therapy. As a consequence of this collaboration, music therapy has earned a solid clinical reputation and is recognized as a valid and effective intervention for this population within the field of psychiatry, in the North Jutland region of Denmark. Additionally, in 2015 music therapy was recommended in the national guidelines for treatment of patients diagnosed with borderline personality disorder, based on recognized clinical practice (Sundhedsstyrelsen, 2015). Despite this recognition, there are ongoing requests from the Danish Health Service for more rigorous evidence for the use of music therapy with this population.

A number of small-scale studies (Hannibal, 1999, 2005, 2002, 2008; Hannibal \& Pedersen, 2000; Hannibal, Petersen, Windfelt, \& Skadhede, 2011; Hannibal, Pedersen, Egelund, Hestbæk, \& Munk-Jørgensen, 2012a; Pedersen, 2002, 2003) have been conducted. These studies show that adherence to treatment is high and dropout is relatively low (10-11\%). One study (Hannibal et al., 2011) documented that group music therapy in combination with other treatments in a day treatment program with patients diagnosed with a personality disorder was beneficial. Yet, the contribution from music therapy was not specified since the patients received six different types of interventions. Based on clinical notes, the impression was that the open unstructured improvisation was very challenging for some patients and that the experience of these individuals could affect outcomes for the whole group. Therefore, it was postulated that introduction to musical expression needed to be done without creating high arousal, because the risk of stimulation insecures attachment systems, and thereby increases negative transference towards the method and/or music. But when the group acknowledged the music as a safe space, it was seen to help facilitate expression, engagement, and interaction among the group members, which supported a sense of group cohesion and the ability to use music for expression. Sessions also included receptive music therapy where, each week, one patient presented a piece of music for the group to listen to. This was both challenging but also very rewarding. The process supported patients in presenting themselves in a new and different way, and the responses from other group members helped to build group cohesion and increased mentalizing process in the group. This process also fostered shared empathy among the group members. The group music therapy study also included data from questionnaires, and these showed a general high satisfaction with music therapy and the patients that received music therapy experienced increased function and reduced personality severity index symptoms (PSI - SCL-90) (Hannibal, 2008, Hannibal et al., 2011). However, findings also suggested that for some patients, group music therapy was a challenge. This was seen in differences in outcomes among the groups. Some groups had high adherence, some average, and some low. Since the treatment, as mentioned, was multimodal, it was not possible to assess the specific contribution from music therapy for this population. In another study (Petersen et al. 2008) looking at the overall outcome of the day treatment program showed reductions in acute and prolonged hospitalizations, suicide attempts, and stabilization in psychosocial functioning.

\section{The PROMT manual}

As a first step for preparing a larger outcome study for this population, a pilot study was conducted in the period from 2012-2014 at the Music Therapy Clinic, testing the feasibility of the research design, treatment doses and frequency, and a treatment manual guide named The Process Oriented Music Therapy manual (PROMT) was devel- 
oped. The development of the treatment manual guide was inspired by analytically oriented music therapy (AOMT) $^{1}$ (Bruscia, 1998; Pedersen 2002, 2014) and mentalization-based treatment (MBT) (Bateman \& Fonagy, 2004, 2006). AOMT has represented a central model in music therapy for the last 25 years (Wigram, Pedersen, \& Bonde, 2002). Since 2000, MBT has been introduced as a new psychotherapy treatment paradigm for patients with personality disorders, and since 2003, MBT has also been integrated into the treatment of patients in music therapy (Hannibal, 2008, 2017; Hannibal et al., 2011; Hannibal \& Schwantes, 2017). MBT is based on the concept of mentalization. Mentalization refers to the process by which "we" make sense of each other and ourselves, implicitly and explicitly, in terms of subjective states and mental processes. When the ability to mentalize is compromised, subjective internal experiences and the interpersonal world stop making sense (Daubney \& Bateman, 2015). MBT has some basic principles for treatment that also seemed applicable in music therapy, and these were incorporated with AOMT into a treatment manual named Process Oriented Music Therapy (PROMT, Hannibal et al., 2012). For more information about mentalizing in the music we refer to (Strehlow \& Hannibal, in press).

The PROMT manual has four levels of principles inspired by Waltz et al. (1993) and Rolvsjord et al. (2005): (1) Unique and essential, (2) Essential but not unique, (3) Acceptable but not necessary, (4) Not acceptable (proscribed). The development of the manual was needed to help minimize treatment infidelity and formulated using treatment principles, rather than formulating direct instructions, where the aim is to investigate complex interventions as recommended by Hawe, Shiell, and Riley (2004). This principle was rooted in experience from a previous, but not published pilot study (2010-2012) with this population with no treatment manual, where the research design was inspired by a study conducted with patient's with depression (Erkkilä et al., 2011). In this previous pilot, two out of three participants dropped out, the selection of musical instruments was experienced as limiting, and it was therefor decided to develop a manual for this specific population. All the elements of the manual are shown in short form in Appendix 1.

\section{The Rationale for Music Therapy with People with Personality Disorders}

There are no specific treatment models within music therapy theory that provide a rationale for the implementation of music therapy for people with personality disorders. Odell-Miller (2007) showed in her doctoral dissertation that "a psychoanalytically informed model with music-making through improvisation and interpretation is indicated for this group of people, who need to address the meaning and understand psychological frameworks for their mental state in order to progress" (p. 370). However, the specific working mechanisms (agents of change) were not specified. Odell-Miller (2016) also referred to Bateman and Fonagy (2004) who stated that one of the reasons for the paucity of research in this field is that this population has been considered treatment-resistant. The development of the MBT model has changed this view of people with personality disorders.

The integration of the MBT model into music therapy is in progress. Based on clinical experience involving group music therapy with this population, the authors are of the opinion that AOMT and MBT have many similar features and fit very well together, particularly in psychiatry formulated in the PROMT manual.

The rationale of the present study is based on a synthesis of many years of clinical experience and the newly gained experience of applying the MBT model as an integrated part of music therapy treatment. Music therapy helps to develop the patient's ability to mentalize implicitly and explicitly by providing a treatment setting in which relational patterns, especially the patient's attachment patterns, can unfold and also be examined, changed, and developed through correctional music-based experiences (Hannibal, 2014). The basic rationale for using music with this population is explained partly by the ability for musical participation to make both explicit and implicit levels 
accessible to the therapeutic proces simultaneously. The implicit is by definition procedural and non-conscious. It is the "how" we relate to the other person unfolded. The explicit level is the "meaning" level and is by definition conscious and includes words, symbols, thoughts, images, and musical artifacts. In musical improvisation we can experience both how we interact and what it means to us. Concepts of the implicit and explicit, in relation to human interaction and psychotherapy, are explored in Daniel Stern's writings (Stern, 1991, 2010). Stern participated in a collaboration called the Boston Proces Change Study Group. In a write up of this group the implicit and explicit (verbal) were described this way:

The implicit is direct, subjective, and "lived through," while the verbal is a delayed view from outside the original implicit experience. This is the "gap" between words and experience that philosophers have pointed to as an inevitable product of translating lived experience into verbal expression. (BPCSG, 2010. p. 182)

Research has shown (Hannibal, 2001) that the preverbal (implicit) level of interaction is enhanced when the relationship shifts from verbal to musical. Musical improvisation can increase the procedural elements for interaction, and thereby bring implicit relational pattens into the open. For more detailed information about the implicit and explicit layers in music therapy see Hannibal (2014).

Especially expressive music has a built in and natural potential to enhance the implicit level of communication and interaction. This potential of music can inspire engagement on a very basic level of interaction and relationship. However, there is also an increased risk of activating attachment systems thereby increasing arousal to critical states such as anxiety and anger. This means that music can provide new experiences of affective attunement, intersubjectivity, and interpersonal regulation (Trondalen, 2016), but also stimulate transference and breakdown in the ability to mentalize. It is, therefore, a balancing act for the music therapist to introduce and explore music with this population in a way that promotes mentalization. Strehlow has researched and described how improvisation can make the patient's experience both supportive and comfortable. On the other hand, improvisation can also be experienced as a threat and make the patient turn away from the therapist (Strehlow et al., 2015). In this respect, music therapy with this population holds the same risk as verbal psychotherapy. But when music is employed as intervention, paying respect to the sensitivity and vulnerability of the patient, both expressive and receptive music therapy methods hold great potential for establishing a relationship and introducing new and more secure attachment patterns. This rationale has not been tested. In general, most verbal patients use oral language as their primary way of engaging and communicating. Thus for patients without a musical background, forms of active music making as a way of engaging and communicating can often be viewed and experienced as something new, unfamiliar, and potentially a threat. Such patients will likely find themselves in unfamiliar territory and experience increased arousal. To address this, the fundamental principal of this manual is that the treatment always starts with, and maintains a focus on, the "here-and-now" for the patient. Even though the patients bring their "history" and past experiences to the therapy (unconscious) but are not aware of it because it is implicit, and even though this history in many case have lead to the present psychiatric condition, the thoughts and emotions that arise in the therapy are rooted in the here-and-now context and interaction. There is awareness of the past but focus on the present. There is a constant potential for the patient to lose their ability to mentalize as a part of their pathology. Therefore the therapist focuses on using any kind of musical or verbal intervention that could promote the therapeutic process in a way that would enhance the patient's ability to mentalize explicitly and implicitly (Hannibal, 2014). As a consequence, in some sessions in this pilot study reported here, there was only verbal interaction, in others musical improvisation, song writing, music reproduction, and/or receptive methods were used. These methods were used to enhance mentalization either by regulating arousal, overcoming pre-mentalization such as pseudo-mentalization or teleological thinking, and to facilitate the forming of a relationship (for 
more detailed information about pre-mentalization see Bateman \& Fonagy 2004, 2006; Hannibal \& Schwantes, 2017). The rationale for this treatment structure is based on the assumption that a higher treatment frequency at the beginning of treatment can compensate for interpersonal vulnerability of overstimulating the attachment system of the participant, leading to possible acting out and termination of treatment often seen in this population.

\section{Aims of study}

The aims of the pilot study were (a) to investigate the feasibility of the research design (referral procedure, data collection procedure, measurement tools and treatment doses/frequency), (b) to develop and evaluate the PROMT treatment manual, and (c) to test the use of flexible and/or multiple interventions as part of the treatment options.

\section{Method}

\section{The Study Design}

This study was constructed as a pre-post design. The participants were diagnosed and assessed at the out-patient unit for patients with personality disorders through their standard procedures using the ICD-10 diagnostic manual (WHO, 1992). Adult patients diagnosed with a personality disorder. The specific diagnoses for each participant is seen in table 1. Patients with the diagnosis DF 60.2, also known as antisocial personality disorder were excluded. This group of individuals was excluded because they are viewed to have severe attachment issues and are often treatment resistant, which is why they were found not suitable for this pilot. However, patients diagnosed within the range of DF 60 - DF 63 were viewed as potential participants for this music therapy study. The patients who were willing to participate were asked to sign an informed consent form that allowed for the collection of data and gave the participants the right to withdraw from the study at any time. The design was approved by the scientific ethical committee in the Region of North Jutland (N-20110013) 2013 and data collection was approved by the Danish Data Protection Agency (2008-58-0028).

The treatment followed the manual PROMT described above (Hannibal et al., 2012). The two clinically involved music therapists received supervision together during treatment, and after the end of treatment, they were interviewed individually in order to evaluate and summarise the treatment manual. An English version of this manual is under development.

\section{Participants}

Study particpants were assessed thoroughly and diagnosed for personality disorders using the ICD-10 diagnostic manual at the outpatient unit for patients with personality disorders. Recruitment was very slow, and some referrals did not meet the inclusion criteria. One reason for the slow referral was related to a different agenda. The referring ward has to perform meaning provide a certain amount of therapy treatments. Assessing patients require many resources, and by referring the assessed particpants to music therapy, they would lose production at the ward. The psychiatric ward conducting the assessment had no active part in the research and would not gain anything by referring particpants to music therapy. Another reason was that more than half of the referred patients did not have a personality disorder diagnosis, and therefore did not fulfill the diagnostic criteria.

In total, four particpants met the inclusion criteria, agreed to participate, and were recruited. Participants were between 24 and 43 years old, and three identified as female and one as male. It was decided that this was enough to complete the pilot study. Table 1 shows participant characteristics and treatment adherence. 
Table 1.

Participants, attended and missed sessions, drop out

\begin{tabular}{|c|c|c|c|c|c|c|}
\hline $\begin{array}{l}\text { Participant } \\
\text { Number }\end{array}$ & Gender & Age & Diagnosis ICD-10 & $\begin{array}{l}\text { Attended } \\
\text { sessions }\end{array}$ & $\begin{array}{l}\text { Missed } \\
\text { sessions }\end{array}$ & $\begin{array}{c}\text { Drop } \\
\text { out }\end{array}$ \\
\hline 1 & $\mathrm{~F}$ & 32 & $\begin{array}{l}\text { DF 60.6. Anxious[avoidant] personality disorder } \\
\text { DF 32.1. Moderate depressive episode }\end{array}$ & 38 & $2(5 \%)$ & 0 \\
\hline 2 & $\mathrm{~F}$ & 41 & $\begin{array}{l}\text { DF 60.0. Paranoid personality disorder } \\
\text { DF 60.5. Anankastic personality disorder } \\
\text { DF 61.0. Mixed personality disorders }\end{array}$ & 35 & $5(12.5 \%)$ & 0 \\
\hline 3 & M & 43 & $\begin{array}{l}\text { DF 60.31. Emotionally unstable personality disorder, } \\
\text { Borderline type } \\
\text { DF 43.2. Adjustment disorders }\end{array}$ & 38 & $2(5 \%)$ & 0 \\
\hline 4 & $\mathrm{~F}$ & 26 & $\begin{array}{l}\text { DF 60.31. Emotionally unstable personality disorder, } \\
\text { Borderline type }\end{array}$ & 24 & $16(40 \%)$ & 0 \\
\hline
\end{tabular}

\section{Procedure}

The particpants met with one of the primary researchers who informed each patient about the research, assisted them when signing the consent form, and was present when they filled out questionnaires for the pre-treatment data collection. This primary researcher did not participate in the treatment itself. The initial three sessions of music therapy were trial sessions. Particpants received a treatment frequency of music therapy twice weekly for 13 weeks, and once weekly for a following 14 weeks, making a total of 40 sessions. Cancelled sessions were not rescheduled. In some cases, summer and/or winter breaks interrupted the flow of the treatment. Therefore, while an equal amount of treatment sessions was offered to all particpants, there was some difference in the total time period of treatment for the four participants. The only exception was for one patient who was very unstable and only participated in 24 sessions. After completing treatment, the particpants met with the primary researcher again and the posttreatment data were collected.

\section{Assessment Tools}

Data for outcome variables were collected before and after the treatment period. Primary outcome variables were The Revised Adult Attachment Scale (RAAS; Collins, 1996); The Inventory of Interpersonal Problems (IIP; Horowitz et al.,1993); and The World Health Organization Quality of Life, WHOQOL; WHO, 1991). Secondary outcome variables were the Symptom Check List-90SCL-90-R; Derogatis, 1994); and the anxiety subscale of the Hospital Anxiety and Depression Scale (HADS-A; Zigmond \& Snaith, 1983). The quality of the therapeutic alliance was assessed after 40 sessions by the Helping Alliance Questionnaire-II (HAQ-II; Luborsky et al., 1996). Due to the pilot and exploratory nature of this study, multiple measures were used in an effort to determine which measures might best capture change resulting from music therapy in individuals with personality disorders.

Symptom Check List -90 (SCL-90; Derogatis, 1994). SCL-90 is a self-report questionnaire. The questionnaire has 90 items and uses a five step Likert scale. There are nine categories of symptoms: Somatization, obsessive-compulsive, interpersonal sensitivity, depression, anxiety, hostility, phobic anxiety, paranoid ideation, psychoticism. The different group of symptoms are operationalized by asking about behaviour, experiences, perceptions ect related to each category. One symptom group (depression) has as much as 13 items, and other groups have fewer. The scoring produces a General Severity 
Index that reflects the overall level of all symptoms. This tool is widely utilised to assess the symptoms as perceived by the patient. The internal consistency (?- coefficient between .84 and .87) test-retest is reported high (Derogatis et al., 1974). It is therefore often used as an outcome measure in research studies. It has been used as such in research by Petersen et al. (2008) with people with personality disorders, and was therefore included in this study.

The Revised Adult Attachment Scale (RAAS; Collins, 1996). The RAAS questionnaire was used to measure attachment style and interaction patterns. This is an 18-item selfreport inventory scale with scores on each item ranging from 1 (lowest possible score, indicating severe attachment problems) to 4 (highest possible score, indicating wellfunctioning attachment). The scores from the 18 items is then calculated into three scales: close, dependent, and anxiety. The different scales were tested for internal consistency, and Collins (1996) reported that "Cronbach's alphas for the close, dependent, and anxiety subscales were .77, .78, and .85, respectively" (p. 814).

The Inventory of Interpersonal Problems (IIP; Horowitz, Rosenburg, \& Bartholomew, 1993). The IIP Circumplex version (IIP-C) was used to identify dysfunctional patterns of interpersonal interactions. The questionnaire "consists of 127 items covering eight dimensions of interpersonal problems: domineering, intrusive, overly nurturing, exploitable, non-assertive, socially avoidant, cold and vindictive" (Petersen et al. 2008. p. 3 ). The mean score provides information on the overall interpersonal functioning and is widely employed in psychotherapy research. A lowering of the score indicates fewer dysfunctions. Paivio and Bahr (1998) "reported test-retest reliability between .89 and .98." (p. 396).

The Sense of Coherence Scale (SOC; Antonovsky, 1979). The SOC questionnaire was developed from the salutogenic model into a full version with 29 questions and a short version with 13 questions to reflect a stable health potential not influenced by negative life events. However, it can also be used to study the effects of psychotherapy over time. The short version used here (SOC-13) is a 13-item measurement of factors that may indicate improvement (or deterioration) of health. The respondents answer each question on a 7-point Likert scale. A high score reflects a stable health potential composed of three dimensions of coherence: understandability, manageability, meaningfulness (these dimensions or sub-scales cannot be used in the SOC-13). The Cronbach $\alpha$ of the SOC-13 has been reported to range from 0.70 to 0.92 (Eriksson \& Lindström, 2005).

The World Health Organization Quality of Life (WHOQOL; World Health Organization, 1991). In 1991, a project was initiated with the aim of developing an international, cross-culturally comparable quality of life (QoL) assessment instrument. "Quality of life is defined as an individual's perception of their position in life in the context of the culture and value systems in which they live and in relation to their goals, expectations, standards and concerns" (WHOQoL Group, 1993, p. 153). The WHOQOL-BREF instrument used in this study is a shorter version of the original 100 item self-report questionnaire, comprising 26 items measuring four domains: physical health, psychological health, social relationships, and environment. In each question, the respondent reports their QoL in the four domains on a 5-point Likert scale. A high score reflects the subjective experience of high QoL. Internal consistency (Cronbach alphas) range between of 0.65 to 0.93 (WHOQOL Group, 1998).

Attachment Patterns. A key goal of the testing procedure was to find a tool that could monitor changes in participants' attachment patterns. Two questionnaires were selected for this purpose: the IIP (Horowitz et al., 1993) and the RAAS (Collins, 1996).

Session note formats. One unresolved issue relates to the format of the therapist's session notes. During the study, several different therapy report sheets were in use, but no final format has been developed. 


\section{Data Collection and Analysis}

All data outcome variables were collected pre and post-treatment as close to treatment start and end dates as possible. Descriptive analyses were made in Excel for Mac version 14.0.0. The effect size was calculated using a web-based tool (http://www.danielsoper.com/statcalc3/calc.aspx?id $=48$ ).

All treatment sessions were audio recorded, and the two music therapists made session notes in a note format that was modified through the datacollecting proces. All the session note formats included information about session number, date, events/topics from the session, and notes about active and receptive methods. After termination, a specific note format summarized the case process related to the aim of the treatment. The notes were only used for therapist to keep track of the therapeutic process and as basis for the short case vingettes (see below).

After the end of treatment, the therapists were interviewed about their use of the PROMT manual. The interviews were semistructured. They lasted about one hour and the interviewer (primary researcher) used the following same five questions for each principle of the PROMT manual: 1) Did you follow the principles? 2) Were there deviations from the manual? 3) Did you review the principles before each session? 4) Would you use the same principles again with this population, and 5) Did you encounter missing items or items that were misplaced? The interview was audio recorded and transcriped. The data was analysed using open coding. The findings are summirised in the presentation of the manual below.

\section{Results}

The results section describes the findings from the outcome variables. It also provides four short case vignettes related to the outcome variables, clinical impressions from the therapy process, and a summary of the interview with the therapists in relation to the PROMT manual.

\section{Questionnaires}

Since there were only four participants in this study, the quantitative findings are only reported in relation to the feasibility of the test. This means that the findings do not provide information about the effect of treatment but provide information on which measurement tools could be feasible in a larger study. Effect size was calculated to get a preliminary impression of possible outcomes, knowing that the results would be highly unrealible due to the small sample size.

Attendance to treatment showed that patients 1,2 and 3 all had high attendance, while patient 4's attendance was very unstable. Nevertheless, their HAQ-II score was high. The general impression is that a low alliance score is often associated with dropping out of treatment. In this study, none of the patients dropped out. HAQ-II was measured after 40 sessions. See table 2 for means and standard deviations. When dichotomized, low alliance is $\leq 4.92$ and high alliance is $>4.92$ in Johanson and Eklund (2006, as cited in, Sharf, Primavera \& Diener, 2010). Patients 1 and 4 were in the high group while patients 2 and 3 were in the low group (See Table 2). This variance is interesting because it illustrates two things: a) low alliance score does not equal dropout, and $\mathrm{b}$ ) a high alliance score does not always mean high attendance. It is positive that the overall alliance score is high, and it corresponds with the RAAS scores as well (se below).

\section{Outcome Measures}

All pre and post scores for the outcome measures pooled can be seen in Table 3 . The findings in the pre and post measures are presented here to indicate their relevance as measurement tools in a future study design. 
Table 2

HAq-II scores for each participant and Average HAq-II score after 40 sessions

\begin{tabular}{|c|c|c|}
\hline Participant Number & HAq-II score & \\
\hline 1 & 5.58 & \\
\hline 2 & 4.57 & \\
\hline 3 & 4.63 & \\
\hline 4 & 5.21 & std \\
\hline Variable & Mean & 0.42 \\
\hline HAq-II & 5.00 & \\
\hline
\end{tabular}

The SCL-90 self-report questionnaire was unfortunately not administrated in its full length due to a trivial printing error. Questions 11-31 are missing for all four participants, so the results are not reliable and they will not be included in this evaluation.

The IIP targets interpersonal dysfunction. Results for the IIP showed a small decrease for patient 1 , a larger decrease for patient 2 , and an increase for patients 3 and 4. The effect size was very small. Despite this finding, the scale is assessed as relevant for a future study, given two reasons: (a) the broad use of this scale within research with this population makes it relevant, and (b) the possibility of a comparison between IIP and RAAS, which is of great relevance because attachment style and interpersonal relational problems are related.

HADS- $A$ targets the level of anxiety. On average the changes were small. Despite differences in the individual changes between patients, HADS- $A$ is a valid tool to identify the level of distress in the patientst's experience, broadly used in research and therefore recommended for future studies.

The SOC targets salutogenic thinking. All patients scored low $(<50)$ at the beginning of treatment. Since the aim of a future study is not specifically to increase the patients' sense of coherence but to increase the ability to mentalize on a moment to moment basis, the scale does not seem to contribute relevant information and is therefore not recommended for future studies.

WHOQOL targets the self-reported quality of life. Effect sizes for the individual parameters varied from small to medium (psychological domain. Two parameters showed decrease in effect size. Based on the findings, the scale seems to be able to target different aspects of how patients subjectively experience their life quality in general and is recommended for future studies.

RAAS targets attachment style and is essential to test the basic hypothesis that music therapy can change attachment style in patients with personality disorders. RAAS gave very interesting results. RAAS have four scales, relating to specific attachment styles: Secure (ES: 0.84), Dependent (ES: $2.0 \mathrm{p}<0.05$ ), Anxiety (ES: 0.24) and Avoidance (ES: 0.84). Findings indicate that the questionnaire is feasible with this population and relevant for this treatment modality. The findings also show an increase in secure attachment and decrease in dependency and avoidance attachment patterns.

In addition to results from the quantative data, qualitative data such as session notes also showed that the patients used a variety of music therapy interventions and that all four patients had individual intervention profiles. Patient 1 preferred to use improvisation. Partient 2 had difficulties improvising in the beginning, so receptive methods were introduced, and improvisation became achievable in later sessions. For partient 3 , improvising was the primary music therapy intervention, but it proved a consistent challenge in every session. Partient 4's musical use was marginal, as she found it extremely challenging. This confirms our initial findings, that each client will need an 
Table 3

Pre and post Outcome Variables

Variables: SCL-90: Symptom Check List -90, IIP: Inventory of Interpersonal Problems, HADS a: Hospital Anxiety Depression Scale a, SOC: Sense Of Coherence, WOHQOL-BREF: WHO Quality Of Life. RAAS: Revised Adult Attachment Scale, HAQ-II: Helping Alliance Questionnaire II.

^ decrease, * low effect size, **moderate effect size, ***High effect size, ${ }^{* * * *}$ significant

\begin{tabular}{|c|c|c|c|c|c|}
\hline Variable & Pre Average & SD & Post Average & SD & Cohen's d \\
\hline IIP average & 2.28 & 0.07 & 2.27 & 0.31 & 0.04 \\
\hline HADS a & 13.12 & 2.13 & 13.00 & 2.55 & 0.05 \\
\hline SOC & 33 & 5.34 & 34.25 & 6.80 & $0.24^{*}$ \\
\hline \multicolumn{6}{|l|}{ WHOQOL-BREF } \\
\hline Life quality & 2 & 0.71 & 2.25 & 1.30 & $0.23^{*}$ \\
\hline Physical health & 2 & 1.22 & 1.50 & 0.50 & $0.52^{\wedge * *}$ \\
\hline Physical domain & 65 & 19.26 & 61 & 9.54 & $0.26^{\wedge}$ \\
\hline Psychological domain & 38 & 6.63 & 43 & 12.12 & $0.51^{* *}$ \\
\hline Social domain & 30 & 3.46 & 33 & 13.08 & $0.31^{*}$ \\
\hline Environment domain & 68 & 4.00 & 7 & 23.75 & $0.64^{* *}$ \\
\hline \multicolumn{6}{|l|}{ RAAS } \\
\hline Secure & 2.62 & 0.62 & 2.99 & 0.13 & $0.84^{* \star *}$ \\
\hline Dependent & 2.33 & 0.23 & 1.62 & 0.43 & $2.00^{\star \star * *}$ \\
\hline Anxiety & 2.99 & 0.54 & 2.88 & 0.43 & $0.24^{*}$ \\
\hline Avoidance & 2.36 & 0.36 & 2.02 & 0.43 & $0.84^{* \star *}$ \\
\hline
\end{tabular}

intervention profile matching their individual capability and therapteutic needs. The verbal dialogue was a necessary element in every session.

\section{Evaluation of Manual}

Two years after termination of treatment, the two clinical music therapists were interviewed by one of the primary researchers. The delay in evaluating PROMT was a disadvantage, and conducting the interview sooner after the termination of the clinical trails would have been preferable. The delay was a consequence of an unclear evaluation procedure. The interviews were conducted despite this disadvantage, and it was seen as the most obvious method to use.

The findings confirmed that both therapists used the manual, that they found it useful, and that the principles were suitable when working with this population. They also made critical comments regarding the manual and formulated suggestions for improvements. The issue of understanding and recognizing mentalization and mentalization breakdown in the musical process was not described in the manual and consequently, there are no principles for how to act or intervene in such situations. The only "help" given in PROMT in relation to this issue was more general and related to the arousal regulation and the overall observation of the patients' mentalizing ability in the verbal context. The therapists also observed and expressed during the interview here that some parts of the manual targeted the treatment process in general and some were more specific to this specific population. In a future experimental study, an updated 
version of PROMT is needed. In this updated version principles for how to engage and stimulate the mentalizing process in the music should be more explicit. Nevertheless, the pilot study also gave ideas for how to understand the possibilities and risks in improvising, songwriting, and in other music therapy interventions.

\section{Four Short Case Vignettes}

The following section presents short vignettes of each of the four cases. It is based on the questionnaires, descriptive data, and on the therapists' summaries of the therapy processes in relation to the aims of the study.

Partient 1 was a 32-year-old woman. Her diagnoses were F60.6 Anxious/avoidant - personality disorder and F32.1 Moderate depressive episode - affective disorder. Her depressive symptoms were dominant and she struggled with a constant urge to commit suicide. She had attempted suicide once. She strongly believed that she was "contaminating" her surroundings and therefore she could not engage with other people. She had planned to commit suicide after her birthday because "everybody would be happy....That would be a good time to kill myself", she stated. She was very isolated. In the therapy sessions, the focus was on increasing her ability to engage, connect and share with other people, and to experience intersubjectivity. Her mentalizing capacity was very low, and changing her view of herself was difficult. However, during sessions she was able to form an alliance with the therapist, and when the therapy ended, she described that the most important thing she had achieved during the treatment was staying alive. Separation and termination were very difficult for her and this was documented in the outcome variables, all illustrating an increase in symptoms at the post treatment measurement. One issue that contributed to her state of mind was a lack of information about the possible continuation of the treatment. This led to uncertainty, as the question of whether her treatment should continue not was settled until 6 months after the 40 sessions were terminated. It was therefore decided to continue music therapy until she could continue in verbal psychotherapy. This led to a decrease in symptoms. Her use of the music often consisted of improvisations on the keyboard. Her style of playing reflected her anxious personality, but the music became a sanctuary for her. The improvisations helped to regulate anxiety and to permit engagement with another person as well as provide a context where she dared to let her self be attuned by another person. The musical relationship also enhanced the attachment system, the participant showed a change to less dependency and less avoidance, and she was able to form a strong alliance with the therapist. Her level of interpersonal problems and her level of anxiety became marginally lower. Quality of life decreased. This may seem paradoxical, but the change in the data is seen as a confirmation of how stressful termination of therapy can be, and thereby also how it can decrease quality of life, even though the other issues are improved. This phenomenon is seen often with this population, as separation may increase distress.

Patient 2 was a 41-year-old woman. Her diagnoses were F60.0 Paranoid personality disorder, F60.5 Anankastic personality disorder, and F61.0 Mixed personality disorders. The treatment quickly revealed her interpersonal sensitivity and her difficulty in sharing emotions. Musical improvisation in the first session provided contact to sadness and loss which were surprising and difficult for her to deal with. In the first part of the therapy, the intention was to use music as a media for emotional expression and clarification, but instead, it was overwhelming and made her distance herself in the therapeutic relationship. This changed when a receptive approach was introduced, where she used music listening to engage in an old, buried, and traumatic loss. In session 26 she announced that she wanted to work with her personality disorder issues and explore these through expressive music therapy methods. This continued in the last part of the treatment. In the active musical context she was able to investigate interaction patterns through musical improvisation. The receptive music therapy helped her investigate, develop, and transform her passive state into a more active state and thereby improve her self-agency. Her data indicated an increase in anxiety as termina- 
tion was imminent but also a more secure attachment and less dependent and anxious attachment style. Her paranoia was bearable and she continued in verbal group therapy. In relation to attachment, she developed a more secure and less dependent and anxious attachment, but her avoidance increased. Her alliance score was the lowest of the four, and below 4.92. Her interpersonal problems decreased, but her anxiety level (HADS) increased. Quality of life showed both increases and decreases in the different variables. The changes in the data illustrates her process. She was more aware of how interpersonal engagement could evoke strong feelings, but her mentalizing capablility was not yet able to give her stability in these situations.

Partient 3 was a 43-year-old male. He was diagnosed with F60.31 Emotionally unstable personality disorder, Borderline type, and F43.2 Adjustment disorders. While on a waiting list for another treatment, he was offered enrollment in this study, and he attended 38 out of 40 planned sessions. Cancellations were due to physical illness. He was rarely on time, often due to transportation issues (such as skipping a bus if there were too many people in it), but very committed once present. He came across as very eloquent and reflective, and he preferred the verbal part of the therapy. Throughout the course of the therapy, he was noticeably ambivalent and worried about playing the instruments. In six sessions spread out during the course of treatment, he was able to manage the emotional stress and play music. Active music therapy was challenging and created ambivalence. When not playing, he felt like he ought to, and at the same time, he regretted not having done so by the end of the session. At times, playing would move him to tears, and he asked for the therapy to be continued while waiting for other treatment. In relation to attachment, he increased his secure attachment, decreased his dependency and avoidance, but had no change on the anxiety scale. His alliance score was below 4.92. The IIP showed an increase, but HADS decreased significantly (15 to 10). Quality of life increased on all parameters. The data illustrate that even though music can be a stress factor and difficult to use, it is still possible to build an alliance and reduce symptoms.

Patient 4 was a 26-year-old woman. She was diagnosed with F60.31 Emotionally unstable personality disorder, Borderline type. She suffered from very low self-esteem, and her therapy was characterised by extreme instability. She only attended 24 sessions out of the 40 planned, and a termination of the treatment was under consideration. After session 10, the therapeutic alliance was renegotiated, and her main challenge, playing music, was eliminated. Subsequently, her attendance became more regular, and though the music activity shifted into music listening, in some sessions she was still able to engage in other musical activities. In her daily life she would use music listening to regulate her arousal when challenged. The music therapy sessions provided her with a confidential and trusting space in which she was able to address difficult issues, even after having omitted very essential information from the therapist during the first part of her therapy. In relation to attachment style, her security increased (doubled), dependency and avoidance decreased, but anxiety increased. Her alliance score was high (5.21), even though her attendance was very irregular. Quality of life decreased in some parameters, but otherwise stayed the same. The data corresponded with the process. She was very unstable, and trusting the therapist took a long time. But at the same time her attachment scores showed a large change, suggesting that she had formed some attachment to the therapist, and the alliance was high. This is an example of how difficult it can be to establish a working alliance with this client group, but also exemplifies that it can be done.

The four case vignettes illustrate the diverse ways in which music therapy may unfold. They also illustrate that the patients' attachment style was changed through the treatment to more secure and less avoidant and dependent, despite the diversity in their individual use of music and level of attandance. However, changes in the IIP did not always correspond directly, which might be due to individual issues for each client, or might also show that alliance, attachment, and interpersonal problems are not directly comparable among patients. 
The use of music was performed very individually, and the patients' ability to profit from different kinds of music therapy interventions is reflected in this. This diversity in intervention profile confirmed our view that the use of only one music therapy intervention (improvisation) would have made alliance formation difficult (in at least two of these cases), because there were negative reactions to engaging in unfamiliar and new ways of expression.

\section{Discussion}

The discussion will focus on the presented aims: (a) to investigate the feasibility of the research design (referral, data collection procedure, measurement tools, time points, and treatment doses/frequency), (b) to develop and test a treatment manual, and (c) to test the use of flexible/multiple interventions as part of the treatment options. Finally, the discussion includes some reflections on the theoretical model of MBT and the rationale for integrating MBT in music therapy.

\section{The Research Design}

This design was shown to be feasible both in relation to procedures of referral, data collection, and measurement tools. Based on the results, a future study should include several questionnaires as pre and post-tests (SCL-90r, HADS-A, IIP, WHOQOL-brief and $R A A S$ ). Despite the problems with $S C L-90-R$ scale we consider $S C L-90-R$ to be a usable and relevant questionnaire in a future study because it is widely used in research with this population, and in other studies it has enabled the identification of important changes (Hannibal et al., 2011; Petersen et al., 2008). Patient-therapist alliance should be measured after the initial five sessions and after treatment (HAq-II) in order to gather a preliminary correlation between alliance and attachment.

\section{Session Notes}

The role of qualitative data in a future mixed methods design has not been clarified. However, looking at the pilot study as a strict pre-post design, the tools in use worked well.

\section{Time Points and Frequency}

Another question relates to the data collection time points. It became clear that termination of treatment in most cases was followed by an increase in symptoms related to the participants' difficulties in terminating a therapeutic relationship. The question is whether collecting data some weeks before the final sessions would give a more reliable view on the participants' progress. The problem can be viewed in two ways: (a) collecting data three to four weeks before the final session could provide more reliable data on the development of alliance, and the anxiety related to the termination process would not contaminate the outcome of treatment; (b) a final deterioration, as shown in a post-test after the final session, is a clear sign of the participant not being in a stable condition. Consequently, the second solution shows a reduced ability to mentalize, increase in symptoms and acting out. Therefore, collecting data after termination will provide the most reliable and valid data. One solution to this dilemma is to include an extra data collection point after 30 sessions. This would confirm progress within the framework of treatment and clarify the amount of stress caused by the termination. In some cases, 40 sessions were not enough to reach a stable state of mind where the participant could manage their illness. In some cases, 40 sessions were enough to ensure that the participant was in a stable condition. The low dropout rate in the study and the high adherence in three of the cases suggests an initial start with two sessions a week is feasible. But no data directly address this treatment structure and how it is perceived by the participants. However, experiences from group music therapy (Hannibal et al. 2011) support the conclusion that this structure can be beneficial. 


\section{The Treatment Manual}

The manual was a functional guide for the therapists. They had both participated in its development, and therefore they were familiar with its content, in theory and in practice. The interview confirmed this impression. Yet it is clear to the authors that the PROMT manual needs to be restructured. It must include more specific instructions on how to keep a mentalizing perspective in the music and how to handle breakdowns in mentalizing capacity by the participant or the therapist in the music. It is also clear that basic training in MBT would be beneficial since verbal conversation was part of every session. The interview analysis confirmed what other studies (Strehlow et al., 2015) performed after this pilot study also show, that engaging through music can be overwhelming and create a breakdown in the mentalizing capacity.

\section{Mono or Multiple Interventions}

One important issue is related to the question of using only one type of intervention, such as improvisation, or using flexible musical interventions. From a research point of view, there is no doubt that a mono intervention (improvisation) provides a more reliable and valid approach in respect to assessing the effectiveness of improvisation as the independent variable. Yet, this had proven unsuccesful in a previous pilot study with the same population (2010-2012).Two partients dropped out, and only one completed treatment. For the present study, it was clear that a flexible intervention strategy was important, and the music therapist individualized the use of music. None of the four cases had an identical intervention profile. This raises the question of how suitable improvisation is with this population. In other studies, improvisation has worked well (Hannibal, 2001; Pedersen, 2003), and in Belgium, a mono-intervention strategy has been reported to work (de Backer, 2016). On the other hand, it is the reality of music therapy in psychiatric settings in Denmark that music therapists use receptive interventions more than improvisation (Lund \& Fønsbo, 2012). The reason for this is unclear. It may be due to the treatment program or to other factors. A future study will need to balance this agenda between high validity and reliability and high compliance and adherence to treatment.

\section{Theoretical Model}

The theoretical model of mentalization-based treatment (MBT) is used in Denmark (Hannibal et al., 2012b, 2014), UK (Odell-Miller, 2007), and Germany (Strehlow, 2009; Strehlow \& Lindner, 2016). These publications show that this model can be seen as an applicable theoretical model for music therapy. The MBT model has substantial implications for understanding the therapeutic process and the patients' development. Moreover, it gives important recommendations to the therapist. We believe and hope to have illustrated, that MBT is a theoretical framework that fits well with music therapy with this population and perhaps also in mental health treatment in general (Hannibal, 2013). However more research is still needed before identification of the mentalizing elements in the music can be done. Strehlow and Hannibal (in press) have already begun this work, where the goal has been to unfold the following questions: How is mentalization in musical context different from mentalization in a verbal context? How does mentalization unfold in a musical context during improvisation? Are there ways of responding through the music that can facilitate mentalization? But for now we can only conclude that the most important aspect is not to change what we do as music therapists but to change how we perceive what is happening in therapy.

All these considerations are of noteworthy importance in the development of a feasible research design. We have reasons to believe that the variables and the treatment frame are feasible in a larger study if the clinical intervention is based on a clearly structured manual and a manual training programme that can ensure treatment fidelity. The length and frequency also seem to work satisfactorily, but 40 sessiones also 
seems too few to help the patients achieve mental and relationship stability. Therefore 60 or more sessions could also be reommended.

The findings of this study support the initial assumption that music therapy using an MBT inspired approach (PROMT) is feasible with patients diagnosed with personality disorder. The findings also suggest that a broad intervention strategy is most appropriate in this setting. Finally, we recommend further mixed method research to explore attachment style, alliance, interpersonal problems, symptoms, and quality of life in a study, and a randomized controlled trial design to rigorously investigate treatment efficacy.

\section{Conclusion}

The outcome of this pilot study encourages the consideration of creating a larger, controlled effect study of music therapy in the treatment of individuals with personality disorders when a revised version of the PROMT manual is completed. After many years of clinical practice, and evidence from small-scale studies showing high adherence and low dropout from treatment, this pilot study confirms that it may be possible to investigate the effect of music therapy with patients diagnosed with personality disorders within a controlled design. Further, we suggest that a revised version of the PROMT manual will be effective in facilitating this design.

\section{Notes}

1. The term Analytically Oriented Music Therapy is no longer used in Denmark. This approach is a strong part of a bigger network of roots defining Music Therapy as the applied concept for all populations. (Pedersen, 2014).

\section{References}

Antonovsky, A. (1987). Unraveling the mystery of health. How people manage stress and stay well. San Fransisco, CA: Jossey-Bass Publishers.

Bateman, A., \& Fonagy, P. (2004). Psychotherapy for borderline personality disorders: Mentalisation-based treatment. Oxford, GBR: Oxford University Press. https://doi.org/ 10.1093/med:psych/9780198527664.001.0001.

Bateman, A., \& Fonagy, P. (2006). Mentalization-based treatment for borderline personality disorder: A practical guide. Oxford, GBR: Oxford University Press. https://doi.org/10.1093/ med/9780198570905.001.0001.

Boston Process Change Study Group. (2010). Change in psychotherapy: A unifying paradigm. York, NY: Norton Professional Books.

Bruscia, K. E. (2006). Dynamics of music psychotherapy. Gilsum: Barcelona publishers.

Daubney, M., \& Bateman, A. (2015). Mentalization-based therapy (MBT): an overview. Australasian Psychiatry, 23(2), 132-135, https://doi.org/10.1177/1039856214566830.

de Backer, J. (2016). The future of music therapy clinical improvisation. In C. Dileo (Ed.), Envisioning the future of music therapy (pp. 112-122). Philadelphia, PA: Temple University.

Collins, N. L. (1996). Working models of attachment: Implications for explanation, emotion and behavior. Journal of Personality and Social Psychology, 71, 810-832, https://doi.org/ 10.1037/0022-3514.71.4.810.

Derogatis, L. R., Lipman, R. S., Rickels, K., Uhlenhuth, E. H., \& Covi, L. (1974). Psychological measurements in psychopharmacology. Basel, Switzerland: Karger Publishers. pp. 79-110, https://doi.org/10.1159/000395070.

Derogatis, L. R. (1994). Symptom checklist-90-Revised: Administration, scoring and procedures manual. Minneapolis, MN: National Computer Systems. 
Erkkilä, J., Punkanen, M., Fachner, J., Ala-Ruona, E., Pöntiö, I., Tervaniemi, M., \& Vanhala...Gold, C. (2011). Individual music therapy for depression: Randomised controlled trial. The British Journal of Psychiatry, 199(2), 132-139, https://doi.org/10.1192/ bjp.bp.110.085431.

Eriksson, M., \& Lindström, B. (2005). Validity of Antonovsky's sense of coherence scale: a systematic review. Journal of Epidemiology \& Community Health, 59(6), 460-466.

Hannibal, N. (1999). The client's potential for therapeutic insight assessed through the ability to reflect verbally and musically. Nordisk Tidsskrift for Musikkterapi, 8(1), 36-46, https://doi.org/10.1080/08098139909477952.

Hannibal, N. (2001). Prceverbal Overføring i Musikterapi: kvalitativ undersøgelse af overføringsprocesser i den musikalske interaktion [Preverbal transference in music therapy: A qualitative investigation of transference process in the musical interaction] (Doctoral dissertation). Aalborg, Denmark: Aalborg University.

Hannibal, N. (2002). Henvisning. assessment og egnethed til musikterapi i psykiatrisk regi. [Refferal, assessment and suitability to music therapy in psychiatry]. Musikterapi $i$ Psykiatrien Online, 3(1), 56-73.

Hannibal, N. (2003). A woman's change from being nobody to somebody: Music therapy with a middle aged, speechless, and self-destructive woman. In S. Hadley (Ed.), Psychodynamic music therapy: Case Studies (pp. 403-413). Gilsum, NH: Barcelona Publishers.

Hannibal, N. (2005). Beskrivelse af patientpopulationen i klinisk musikterapi på fem psykiatriske institutioner i Danmark i perioden august 2003-juli 2004. [Description of the patientpopulation in clinical music therapy on five psychiatric institutions in Denmark in the period from August 2003-July 2004]. Musikterapi i Psykiatrien Online, 4(1), 65-75.

Hannibal, N. (2008). Gruppemusikterapi med patienter med borderlinepersonlighedsforstyrrelse i dagbehandlingsregi. [Group music therapy with patients with borderline-personality disorder in day care treatment]. Musikterapi i psykiatrien: årsskrift, 5(1), 76-101.

Hannibal, N., Petersen, B., Windfelt, M., \& Skadhede, S. (2008). Gruppemusikterapi i Dagbehandlingsregi: Opsamling på perioden 2003 til 2010. [Group Music Therapy in Day care treatment: Summary form the period 2003 to 2010]. Musikterapi i psykiatrien: årsskrift, 6(1), 27-37.

Hannibal, N. (2013). Mentaliseringsbaseret behandling og musikterapi. [Mentalization based treatment and music therapy]. Musikterapi i Psykiatrien Online, 8(1), 4-16.

Hannibal, N. (2014). Implicit and explicit mentalization in music therapy in the psychiatric treatment of people with borderline personality disorder. In J. De Backer \& J. Sutton (Eds.), The music in music therapy: Psychodynamic music therapy in Europe: Clinical, theoretical and research approaches (pp. 211-223). London, GBR: Jessica Kingsley Publishers.

Hannibal, N. (2017). Mentalisering i aktiv musikterapi set i forhold til neuroaffektiv teori. Mentalizing in active music therapy seen in relation to neuroaffective theory. In C. Lindvang \& B. D. Beck (Eds.), Musik, krop og følelser. Neuroaffektive processer i musikterapi (pp. 269-284). Frederiksberg, Denmark: Frydenlund Academic.

Hannibal, N., \& Pedersen, I. N. (2000). Opgørelse af fremmøde-stabilitet for patienter i musikterapi 1997. [Description of the attendance stability for patients in music therapy in 1997]. . Musikterapi i Psykiatrien Online, 2(1), 141-143.

Hannibal, N., Petersen, B., \& Windfeld, M. (2011). Gruppemusikterapi i Dagbehandlingsregi: Opsamling på perioden 2003 til 2010. [Group music therapy in day care treatment]. Musikterapi i Psykiatrien Online, 6(1), 26-37.

Hannibal, N., Pedersen, I. N., Hestbæk, T., Sørensen, T. E., \& Munk-Jørgensen, P. (2012a). Schizophrenia and personality disorder patients' adherence to music therapy. Nordic Journal of Psychiatry, 66, 376-379, https://doi.org/10.3109/08039488.2012.655775. 
Hannibal, N., Pedersen, I. N., Bonde, L. O., Bertelsen, L. R., Dammeyer, C., \& Lund, H. N. (2012b). Manual for procesorienteret musikterapi med personer med bpd. [Manual for process oriented music therapy with people with bpd]. Musikterapi i psykiatrien Online, $7(2)$, 64-80.

Hannibal, N., \& Schwantes, M. (2017). What does music therapy have to offer mentalization based treatment (MBT)? A mentalization-based view on music therapy clinical practice in psychiatry. Voices, 17(2), https://doi.org/10.15845/voices.v17i2.897.

Hawe, P., Shiell, A., \& Riley, T. (2004). Complex interventions: How out of control. British Medical Journal, 328, 1561-1563, https://doi.org/10.1136/bmj.328.7455.1561.

Horowitz, L. M., Rosenberg, S. E., \& Bartholomew, K. (1993). Interpersonal problems, attachment styles, and outcome in brief dynamic psychotherapy. Journal of Consulting Clinical Psychology, 61(4), 549-560, https://doi.org/10.1037/0022-006X.61.4.549.

Johansson, H., \& Eklund, M. (2006). Helping alliance and early dropout from psychiatric outpatient care. Social Psychiatry and Psychiatric Epidemiology, 41(2), 140-147, https://doi.org/ 10.1007/s00127-005-0009-z.

Luborsky, L., Barber, J. P., Siqueland, L., Johnson, S., Najavits, L. M., Frank, A., \& Daley, D. (1996). The revised Helping Alliance questionnaire (HAq-II): Psychometric properties. The Journal Of Psychotherapy Practice and Research, 5, 260-271.

Lund, H. N., \& Fønsbo, C. D. (2012). Musiklyttegrupper - en empirisk undersøgelse af anvendte metoder i psykiatrien. [Music listening groups - an empirical investigation of used methodes in psychiatry]. Musikterapi i psykiatrien, 6(1), 87-101.

Odell-Miller, H. (2007). The practice of music therapy for adults with mental health problems: The relationship between diagnosis and clinical method (Doctoral dissertation). Aalborg, Denmark: Aalborg University. Retrieved from http://vbn.aau.dk/files/41635432/odell_miller.pdf.

Odell-Miller, H. (2016). Music therapy for people with a diagnosis of personality disorder: Considerations of thinking and feeling. In J. Edwards (Ed.), The Oxford handbook of music therapy (pp. 313-334). Oxford, GBR: Oxford University Press.

Pedersen, I. N. (2002). Music therapy with psychiatric clients. In T. T. Wigram., I. N. Pedersen, \& L. O. Bonde (Eds.), A comprehensive guide to music therapy: Theory, clinical practice, research and training (pp. 153-168). London, GBR: Jessica Kingsley Publishers.

Pedersen, I. N. (2003). The revival of the frozen sea urchin: Music therapy with a psychiatric patient. In S. Hadley (Ed.), Psychodynamic music therapy: Case studies (pp. 375-387). Gilsum,NH: Barcelona Publishers. https://doi.org/10.1080/08039480801984271.

Pedersen, I. N. (2014). Analytisk Orienteret Musikterapi (AOM). [Analytic oriented music therapy]. In L. O. Bonde (Ed.), Musikterapi.Teori.Uddannelse.Praksis.Forskning.En håndbog om musikterapi i Danmark. Aarhus, Denmark: Klim Forlaget. [[Music therapy. Theory. Education. Practice. Research. A handbook about music therapy in Denmark]].

Petersen, B., Toft, J., Christensen, N. B., Foldager, L., Munk-Jörgensen, P., Lien, K., \& Valbak, K. (2008). Outcome of a psychotherapeutic programme for patients with severe personality disorders. Nordic Journal of Psychiatry, 62(6), 450-456.

Paivio, S., \& Bahr, L. (1998). Interpersonal problems, working alliance, and outcome in shortterm experiential therapy. Psychotherapy Research, 8(4), 392-407, https://doi.org/10.1080/ 10503309812331332487.

Rolvsjord, R., Gold, C., \& Stige, B. (2005). Research rigour and therapeutic flexibility: Rationale for a therapy manual developed for a randomised controlled trial. Nordic Journal of Music Therapy, 14, 15-32, https://doi.org/10.1080/08098130509478122.

Sharf, J., Primavera, L. H., \& Diener, M. J. (2010). Dropout and therapeutic alliance: A metaanalysis of adult individual psychotherapy. Psychotherapy: Theory, Research, Practice, Training, 47(4), 637-645, https://doi.org/10.1037/a0021175.

Stern, D. (1991). Barnets Interpersonelle Univers [The interpersonal world of the infant: A view from psychoanalysis and developmental psychology]. København, Denmark: Hans Reitzels Forlag. 
Stern, D. (2010). Vitalitetsformer - dynamiske oplevelser i psykologi, kunst, psykoterapi og udvikling [Forms of vitality: Exploring dynamic experience in psychology, the arts, psychotherapy, and development]. København, Denmark: Hans Reitzels Forlag.

Strehlow, G. (2009). The use of music therapy in treating sexually abused children. Nordic Journal of Music Therapy, 18(2), 167-183, https://doi.org/10.1080/08098130903062397.

Strehlow, G., \& Lindner, R. (2016). Music therapy interaction patterns in relation to borderline personality disorder (BPD) patients. Nordic Journal of Music Therapy, 25(2), 134-158, https://doi.org/10.1080/08098131.2015.1011207.

Strehlow, G., \& Hannibal, N. Mentalization in improvisational music therapy. Nordic Journal of Music Therapy, https://doi.org/10.1080/08098131.2019.1574877.

Sundhedsstyrelsen. (2015). National klinisk retningslinje for behandling af emotionel ustabil personlighedsstruktur, borderline type [National clinical guidelins for treatment of emotional unstable personality structure, Borderline type]. Retrieved from https://sundhedsstyrelsen.dk/da/nyheder/2015/ /media/ 80113F052C3A4097B7772B225256895B.ashx.

Trondalen, G. (2016). Relational music therapy: An intersubjective perspective. Dallas, TX: Barcelona Publishers.

Waltz, J., Addis, M. E., Koerner, K., \& Jacobson, N. S. (1993). Testing the integrity of a psychotherapy protocol: Assessment of adherence and competence. Journal of Consulting and Clinical Psychology, 61(4), 620-630, https://doi.org/10.1037/0022-006X.61.4.620.

WHOQoL Group. (1993). Study protocol for the World Health Organization project to develop a Quality of Life assessment instrument (WHOQOL). Quality of Life Research, 2, 153-159, https://doi.org/10.1007/BF00435734.

WHOQoL GROUP. (1998). The World Health Organization quality of life assessment (WHOQOL): Development and general psychometric properties. Social science \& Medicine, 46(12), 1569-1585, https://doi.org/10.1016/S0277-9536(98)00009-4.

Wigram, T., Pedersen, I. N., \& Bonde, L. O. (2002). A comprehensive guide to music therapy: Theory, clinical practice, research and training. London, GBR: Jessica Kingsley Publishers.

World Health Organization. (1992). The ICD-10 classification of mental and behavioural disorders: clinical descriptions and diagnostic guidelines (Vol. 1). World Health Organization.

Zigmond, A. S., \& Snaith, R. P. (1983). The hospital anxiety and depression scale. Acta psychiatrica scandinavica, 67(6), https://doi.org/10.1111/j.1600-0447.1983.tb09716.x.

\section{Appendix}

PROMT:

\section{Category 1: Unique and Essential Therapeutic Principles}

1.1 The therapeutic process is always the central focus of the music therapy work.

1.2 The therapeutic process can focus on reduction of symptoms and/or development of skills/competencies and/or strengthening of resources.

1.3 The therapeutic process always takes place in a perspective of 'here and now,' and the past is only involved in this perspective.

1.4 The therapeutic process concerns both the implicit procedural level and the explicit and declarative level.

1.5 The therapeutic process is not limited to a certain music therapy method (improvisation, composition, reproduction, or music listening).

1.6 The focus for the therapeutic process is relational and communicative competences.

1.7. The therapist has to know and be able to perform "a not knowing stance" in the treatment. (The therapist should aim at preserving an attitude to the client in the verbal parts, in the musical parts, and in the non-verbal communication, which promotes mutual mentalization.)

Category 2: The Essential but not Unique Therapeutic Principles: 
2.1 The therapeutic process is identified in dynamic patterns like defence, transference and counter transference.

2.2 In the therapeutic process creating, developing and maintaining of the therapeutic alliance (cooperation on aims, methods, intimacy, and leadership) is necessary.

2.3 The therapeutic process has regulation of arousal as its focus.

2.4 The therapeutic process can take place through verbal reflection or by musical actions.

Category 3: Acceptable but not Necessary Therapeutic Principles:

3.1 Interventions which curb negative processes and processes which do not promote the ongoing therapeutic process.

3.2 Advice and structuring interventions when the patient cannot cope with the therapeutic process.

Category 4: Not acceptable - Proscribed Therapeutic Principles

4.1 Interventions based solely on methodological or theoretical reasons without involving the perspective of the patient.

4.2 Application of transference to examine unconscious repetitions of earlier behaviour.

4.3 Encouragement of fantasies and free associations about the therapist.

4.4 Application of frustrating and confronting interventions such as for example long silent breaks.

4.5 Mirroring of non-marked (explicit) emotions. 